\title{
Application of intelligent analysis to identify defective vehicle components
}

\author{
Aleksandr Voroshilov ${ }^{1}$, and Polina Buyvol ${ }^{1 *}$ \\ ${ }^{1}$ Kazan Federal University, Syuyumbike Avenue, 10A, Naberezhnye Chelny, 423812, Russia
}

\begin{abstract}
The article shows the possibility of using intelligent analysis in a vehicle service when assessing the vehicle reliability. It was hypothesized that the use of association rules in diagnostics can increase the speed of repairs and the quality of customer service, allowing to identify the nodes that are highly likely to be faulty at the same time. For this, a knowledge base was built from the patterns obtained by applying association rules to the vehicle failure statistics. An application was implemented, which, on its basis, issues recommendations to the repair worker to check certain nodes based on the already identified defective nodes entered into the program. The proposed technique, together with the developed software tool, will optimize the diagnostic processes.
\end{abstract}

\section{Introduction}

The development of technics and technology leads to the fact that it is becoming more and more difficult to provide the consumer with the trouble-free operation of his vehicles. The increasing complexity of the vehicle design associated with the use of new engine types (electric energy and hydrogen cells), the transition to fuel alternative types (biofuels, compressed and liquefied natural gas), its intellectualization, leading to an increase in the share of electrics and electronics, impose new requirements for the specialists' qualifications for the detection and diagnosis of malfunctions. One of the factors to ensure the vehicle competitiveness, especially during the warranty period under the manufacturer's responsibility, is to increase customer loyalty. At the operational stage, this is achieved by high-quality service. The main task in the event of a vehicle breakdown is to find all defective units as quickly and accurately as possible, since one of the ways to improve operational reliability is to reduce the repair time. Since diagnostics is associated with the processing of information large amounts, tools to quickly identify complex interconnections through multivariate analysis are needed.

\section{Theory: methods used in the analysis of vehicle reliability}

Diagnostics and troubleshooting are one of the most important issues in organizing highquality and fast maintenance and repair of technical systems and vehicles, in particular. To improve these technological processes, it is necessary to first determine the most critical

* Corresponding author: skyeyes@mail.ru 
units and the sequence of their check. A vehicle is a complex union of elements that interact and interconnect, therefore, it is necessary to search and apply methods and techniques that take into account the mutual influence of vehicle units and parts on each other when one of them fails.

Common methods for analyzing system reliability are failure tree analysis [1], logicalprobabilistic method [2-3], failure mode and effect analysis [4], multivariate failure analysis [5-6], fuzzy logic [7], finding of failure distribution functions [8], instrumental diagnostics methods [9-10], for example, based on vibration level measurement [11-12]. However, limitations of the first three methods are the lack of deep systemic knowledge about the design and ongoing processes of the system under consideration. Other methods do not allow to take into account the mutual influence of adjacent parts. In this sense, machine learning methods will remove some of the limitations. In addition, extracting hidden knowledge from the available historical data on the phenomena and processes under consideration, it will be possible to discover non-trivial dependencies that are difficult to identify and analyze even for experts. Machine learning techniques have become an important part of data mining engineering research. They have evolved into powerful tools for developing efficient and accurate solutions to many data-driven decision making and optimization problems [13-15].

Association rules are one of the machine learning methods. It allows to identify common sets of objects in a large collection [16]. Association rules have previously been successfully used to predict customer purchases, help diagnose diseases, analyze and predict telecommunications equipment failures, analyze web page visits [17], and identify factors that affect the likelihood and severity of road traffic accidents [18]. The main advantage of association rules is such a form of calculations results presentation, which is easy for human perception and is available for interpretation by programming languages [19]. It was hypothesized that the use of association rules in vehicle diagnostics can improve the level of customer service, allowing to determine the nodes that are highly likely to be faulty at the same time. Thus, the purpose of the study was to develop a mechanism for helping vehicle service repair workers to make decisions when diagnosing failures in the form of recommendations for monitoring the state of "interconnected" nodes based on already detected defective parts.

\section{Results: development of a tool for identifying defective vehicle units}

\subsection{Building a knowledge base using association rules}

To achieve goal to be sought, a method of building a knowledge base using association rules was chosen, which is based on an apriori algorithm capable of processing a significant amount of information in a reasonable time, and as a language for creation - $\mathrm{C}$ \# application, which in this case is optimal for rapid development complex applications for Windows. To apply the apriori algorithm, we used the Deductor Studio environment - a platform for creating complete analytical solutions. Software development was carried out using the Visual Studio IDE, a Microsoft product that is widely used for developing programs in $\mathrm{C}$ \#, and has a free Community version for scientific research, educational projects, and open source projects.

The algorithm of the developed decision support mechanism is as follows: an array of records about faulty vehicle units in a file with the extension .xls (MS Excel format) or .odt (LibreOffice format) is used as the initial data for identification. Each entry must contain the following information: (1) Document number (complaint / work order); (2) VIN (engine number); (3) Group of parts; (4) Subgroup of parts; (5) Detail. 
The document number is not unique, as it can be repeated in different service centers. Likewise, the engine number can also appear several times, since each vehicle can call in different service centers of the service network. Therefore, the concatenation of the "document number" and "engine number" fields is used as the transaction number. The combination of the fields "group of parts", "subgroup of parts" and "part" allows to uniquely identify the defective part.

This file is imported into the Deductor Studio project, where dependencies are displayed using the "Association Rules" handler. It indicates which parts fail at the same time (Fig. 1). For each rule, such objective significance measures are calculated as support (the frequency of parts' combination occurrence in the data array) and confidence (the probability that the rule will turn out to be true), as well as an subjective measure - lift (characterizes the significance of the rule in the form of the strength of the connection between the part- antecedent and detail-consequent) [20].

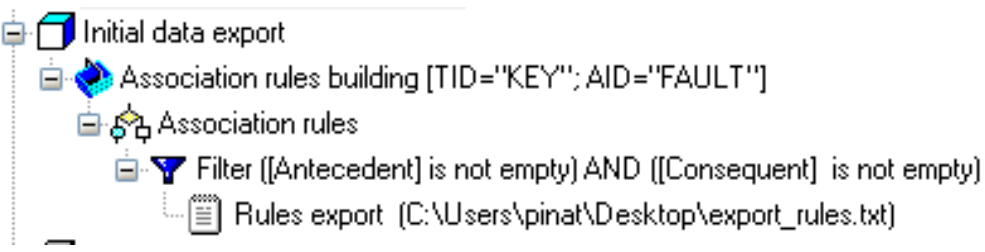

Fig. 1. Built script in Deductor Studio project

As a result of processing complaints data using Deductor Studio, potentially useful rules were derived. They exceed the specified minimum threshold of support and confidence (Table 1). Since the importance of the lift is large, it can be concluded that there is a strong direct connection between the antecedent and the consequent.

Table 1. Obtained meaningful association rules

\begin{tabular}{|c|c|c|c|c|c|}
\hline \multirow{2}{*}{$\begin{array}{l}\text { Rule } \\
\text { num } \\
\text { ber }\end{array}$} & $\begin{array}{l}\text { Antecedent, } \\
\text { group }\end{array}$ & Antecedent, subgroup & Antecedent, detail & \multirow[t]{2}{*}{$\begin{array}{l}\text { Confi- } \\
\text { dence }\end{array}$} & \multirow[t]{2}{*}{ Lift } \\
\hline & $\begin{array}{l}\text { Consequent, } \\
\text { group }\end{array}$ & Consequent, subgroup & Consequent, detail & & \\
\hline \multirow[t]{2}{*}{1} & Brake system & Front working brake and brake drum & Pad & \multirow[t]{2}{*}{76,9} & \multirow[t]{2}{*}{52,5} \\
\hline & Front axle & Front axle and steering knuckle & Support bearing disc & & \\
\hline \multirow[t]{2}{*}{2} & Front axle & Front axle and steering knuckle & Support bearing disc & \multirow[t]{2}{*}{41,7} & \multirow[t]{2}{*}{52,5} \\
\hline & Brake system & Front working brake and brake drum & Pad & & \\
\hline \multirow[t]{2}{*}{3} & Brake system & Bypass brake valve & Dual-magister valve & \multirow[t]{2}{*}{26} & \multirow[t]{2}{*}{9,8} \\
\hline & Devices & Oil pressure sensor & Sensor & & \\
\hline \multirow[t]{2}{*}{4} & Devices & Tyre pressure sensor & Pressure sensor & \multirow[t]{2}{*}{21,2} & \multirow[t]{2}{*}{8} \\
\hline & Devices & Pressure sensor & Sensor & & \\
\hline \multirow[t]{2}{*}{5} & $\begin{array}{l}\text { Electrical } \\
\text { equipment }\end{array}$ & Generator & Relay-regulator & \multirow[t]{2}{*}{41,7} & \multirow[t]{2}{*}{28,8} \\
\hline & Devices & VK403B & Reversing light switch & & \\
\hline \multirow[t]{2}{*}{6} & Cooling system & Fan and its drive & $\begin{array}{l}\text { Electromagnetic clutch } \\
\text { engagement sensor }\end{array}$ & \multirow[t]{2}{*}{26,6} & \multirow[t]{2}{*}{17,2} \\
\hline & Cooling system & Thermostat & Thermostat & & \\
\hline
\end{tabular}




\subsection{Developing an application that makes recommendations for checking nodes}

The file with the resulting association rules is passed to experts or workers using the application. For example, an updated version of the association rules can be sent out regularly by email.

When launching the developed application, it is proposed to select the imported file (Fig. 2).

$\begin{aligned} & \text { Tile location } \\
& \text { Please, specify the location of the association rules } \\
& \text { file (.xlsx format) }\end{aligned}$
\begin{tabular}{ll|}
\hline D:\TRANSLATED_RULES.xlsx & Select \\
\hline & Continue \\
\hline
\end{tabular}

Fig. 2. File with association rules selection form

After adding already identified defective parts, a list of units recommended for inspection is displayed (Fig. 3). For greater convenience, the details proposed for verification are sorted in descending order of the association rules confidence.

\begin{tabular}{|c|c|c|c|c|}
\hline Detail analysis & & & - & $x$ \\
\hline Detail group & \multicolumn{3}{|l|}{ Engine } & Select \\
\hline Detail subgroup & \multicolumn{3}{|l|}{ Exhaust manifolds } & Select \\
\hline Detail & \multicolumn{3}{|l|}{ Exhaust manifold gasket } & Select \\
\hline & & & & Add to list \\
\hline \multicolumn{5}{|l|}{ Listed parts: } \\
\hline Group & Subgtoup & Detail & & \\
\hline Front axle & Front axle and steering knuckle & Thrust bearing washer & \multicolumn{2}{|l|}{ Remove } \\
\hline Brake system & Anti-lock braking system & ECU BOSCH & \multicolumn{2}{|l|}{ Remove } \\
\hline Engine & Exhaust manifolds & Exhaust manifold gasket & \multicolumn{2}{|l|}{ Remove } \\
\hline \multicolumn{5}{|c|}{ Parts recommended for inspection: } \\
\hline Group & Subgroup & Detail & \multicolumn{2}{|l|}{ Confidence } \\
\hline Devices & VK403B & Reversing light switch & \multicolumn{2}{|l|}{60} \\
\hline Brake system & Front working brake and brake drum & pad & \multicolumn{2}{|l|}{41.66667} \\
\hline Devices & Oil pressure gauge gauge & Sensor & \multicolumn{2}{|l|}{21.05263} \\
\hline
\end{tabular}

Fig. 3. The main form of the running application

The application is written using Windows Presentation Foundation (WPF), which allows flexible customization of the visual interface (Fig. 4), as well as the use of the data binding mechanism, which breaks the "hard" connection between the interface and the logic of its execution. In case of significant improvements or integration of an existing application into a package with extended functionality, project development will be much easier.

The architecture of the application is based on the construction of the Model-ViewViewModel (MVVM) pattern - a design pattern focused on modern development platforms, including WPF (Fig. 5). Model includes the logic of working with data and the description 
of fundamental data. A View is a graphical interface focused on presenting data. ViewModel is a layer between data and a graphical interface that contains application logic. Using MVVM in conjunction with the freeware dependency injection library Autofac will also make it much easier to modify and extend the program in the future.

Dependency injection is the process of providing an external dependency to a software component, when an object instructs an external, dedicated general mechanism to build the dependencies it needs. The source code of the application can be downloaded from the link [21].

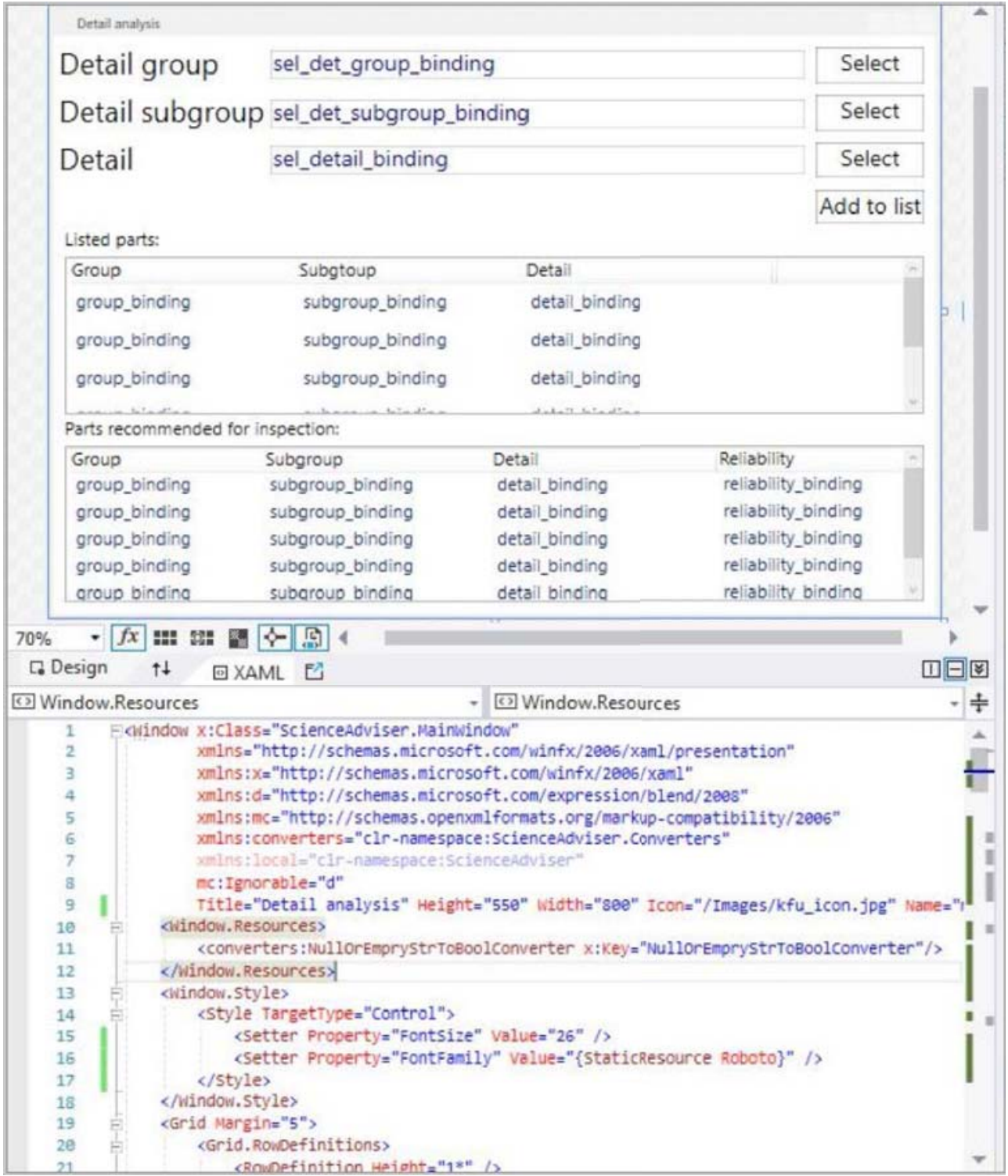

Fig. 4. The application main form in edit mode in Visual Studio 


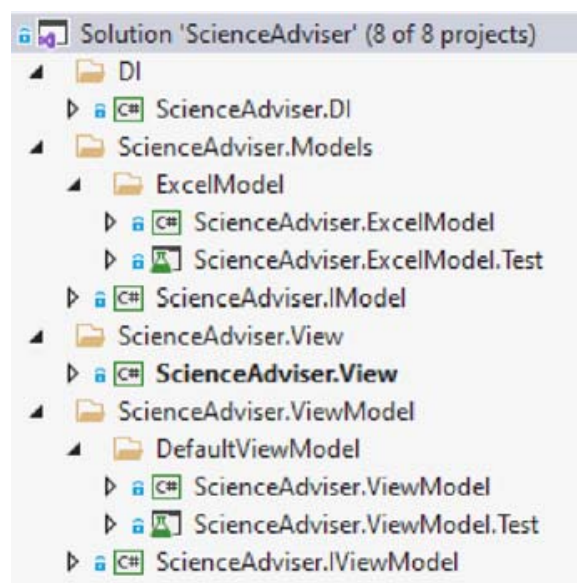

Fig. 5. Project library hierarchy in Visual Studio

Thus, due to the use of modern approaches to software design in project development, the application has the potential for development. The proposed mechanism can subsequently be implemented as a website or mobile application. Also relevant for the project's development is the implementation of the possibility of constant automated updating of the association rules base due to new data arrays from complaints or work order.

\section{Conclusion}

The increasing complexity of the vehicle design poses new challenges for the vehicle manufacturer's branded service system in the form of ensuring timely and high-quality maintenance and repair. The study shows that the use of association rules as one of the data mining methods and the introduction of an application developed on their basis in the branded service system will not only improve the efficiency and quality of repair work, but also ensure the reliability of vehicle operation. When diagnosing a vehicle received for maintenance and repair, the employee, in case of identifying any defective part, receives a list of components generated by the application that must be checked. In addition, rulebased recommendations with high support for the supply chain in the form of a list of parts with the least resource (in particular, non-conforming manufacturer) can be developed, and suppliers or manufacturers of such parts can be identified.

\section{References}

1. Fault tree analysis, URL: http://statistica.ru/knowledge-clusters/technicalsciences/analiz-dereva-otkazov

2. I. A. Ryabinin, A. V. Strukov, Quantitative examples of safety assessment using logical-probabilistic methods, International Journal of Risk Assessment and Management (IJRAM), 21(1/2), doi: 10.1504/IJRAM.2018.090253 (2018)

3. I. Makarova, K. Shubenkova, E. Mukhametdinov, I. Giniyatullin, Selection of the Method to Predict Vehicle Operation Reliability, Lecture Notes in Networks and Systems, 117, pp. 316-328 (2020)

4. I. Makarova, E. Mukhametdinov, V. Mavrin, Unified information environment role to improve the vehicle reliability at life cycle stages during the transition to industry 4.0, 
Proceedings - International Conference on Developments in eSystems Engineering, DeSEVolume October-2019, pp. 800-805 (2019)

5. R.G. Khabibullin, I.V. Makarova, E.I. Belyaev, I.F. Suleimanov, S.S. Pernebekov, U.A., Ussipbayev, A.S., Junusbekov, Z.A. Balabekov, The study and management of reliability parameters for automotive equipment using simulation modeling, Life Science Journal, 10 (12), pp. 828-831 (2013)

6. I. Makarova, R. Khabibullin, A. Belyaev, E. Belyaev, Dealer-service center competitiveness increase using modern management methods, Transport Problems, 7(2), pp. 53-59 (2012)

7. O.P. Yadav, N. Singh et al., A Framework for Reliability Prediction During Product Development Process Incorporating Engineering Judgments, Quality Engineering, 15(4), pp. 649-662 (2003)

8. I. Makarova, K. Shubenkova, P. Buyvol, V. Shepelev, A. Gritsenko, The Role of Reverse Logistics in the Transition to a Circular Economy: Case Study of Automotive Spare Parts Logistics, FME Transactions, 49(1), pp. 173-185 (2021)

9. A. Gritsenko, V. Shepelev, E. Zadorozhnaya, K. Shubenkova, Test diagnostics of engine systems in passenger cars, FME Transactions, 48 (1), pp. 46-52 (2020)

10. A. V. Gritsenko, E. A. Zadorozhnaya, V. D. Shepelev, Diagnostics of friction bearings by oil pressure parameters during cycle-by-cycle loading, Tribology in Industry, 40(2), pp. 300-310 (2018)

11. A. Gritsenko, V. Shepelev, E. Zadorozhnaya, Z. Almetova, A. Burzev, The advancement of the methods of vibro-acoustic control of the ICE gas distribution mechanism, FME Transactions, 48 (1), pp. 127-136 (2020)

12. I. Makarova, E. Mukhametdinov, V. Mavrin, K. Shubenkova, Improvement of the Vehicle Clutch's Diagnosing System with the Use of Vibrodiagnostics, 2018 IEEE International Conference on Technology Management, Operations and Decisions, pp. 101-106 (2018)

13. A. Ragab, M. Koujok, H.Ghezzaz, M.Amazouz, M.-S. Ouali, S.Yacout, Deep understanding in industrial processes by complementing human expertise with interpretable patterns of machine learning, Expert Systems with Applications, 122, pp. 388-405 (2019)

14. M. Drakaki, Y.L. Karnavas, P. Tzionas, I.D. Chasiotis, Recent Developments Towards Industry 4.0 Oriented Predictive Maintenance in Induction Motors, Procedia Computer Science, 180, pp. 943-949 (2021)

15. E. Alpaydin, Introduction to Machine Learning, MIT Press, 712 p. (2020)

16. J. Dongre, G. L. Prajapati, S. V. Tokekar, The role of Apriori algorithm for finding the association rules in Data mining, 2014 International Conference on Issues and Challenges in Intelligent Computing Techniques (ICICT), Ghaziabad, India, pp. 657660, doi: 10.1109/ICICICT.2014.6781357 (2014)

17. S. Luma-Osmani, F. Ismaili, X. Zenuni, B. Raufi, A Systematic Literature Review in Causal Association Rules Mining, 2020 11th IEEE Annual Information Technology, Electronics and Mobile Communication Conference (IEMCON), pp. 0048-0054, doi: 10.1109/IEMCON51383.2020.9284908 (2020)

18. I. Makarova, G. Yakupova, P. Buyvol, E. Mukhametdinov, A. Pashkevich, Association rules to identify factors affecting risk and severity of road accidents, VEHITS 2020 - Proceedings of the 6th International Conference on Vehicle Technology and Intelligent Transport Systems, pp. 614-621 (2020) 
19. An Introduction to Association Rule Analysis, URL: https://loginom.ru/blog/associative-rules

20. L. Zhang, W. Wang, Y. Zhang, Privacy Preserving Association Rule Mining: Taxonomy, Techniques, and Metrics, IEEE Access, 7, pp. 45032-45047, doi: 10.1109/ACCESS.2019.2908452 (2019)

21. Program code of ScienceAdviser, URL: https://github.com/pinatree/ScienceAdviser 